\title{
Prevalence of Dental Caries among Junk Food- and Non-junk Food-eating Schoolchildren in Urban and Rural Areas of Mayiladuthurai, Tamil Nadu, India
}

\author{
Bala Vaishnavi Gunaseelan ${ }^{1}$, Vidhya Gunasekaran²
}

\begin{abstract}
Background: Dental caries is a multifactorial disease. Diet plays an important role in the nutritional status and individual development. Migration of people from rural areas and urbanization cause a change in the lifestyle and dietary habits which in turn affects oral health.

Aim: To assess the prevalence of dental caries in junk food- and non-junk food-eating school students among urban and rural schoolchildren in Mayiladuthurai.

Objective: To identify the role of dietary habits (type of diet, skipping meals, snacking between meals, and frequency of visits to fast-food restaurants) in occurrence and severity of caries.

Materials and methods: In this study, a total of 174 participants were considered, and among them 59 are rural schoolchildren and 115 are urban schoolchildren. Assessment of dental caries based on modern foods was done. A questionnaire was prepared to check the frequency of foods and the student's responses were marked.

Results: Among 59 rural schoolchildren, $80 \%$ have caries and $20 \%$ have no caries. Among 115 urban students, $84 \%$ have caries and $16 \%$ have no caries. Compared to rural schoolchildren, urban schoolchildren are more affected by dental caries.

Conclusion: This study was done to reduce the risk of caries by eliminating the intake of cariogenic food. Our study shows the risk of caries was high among urban schoolchildren.

Keywords: Dental caries, Dietary habits, Mayiladuthurai.

Journal of Scientific Dentistry (2020): 10.5005/jp-journals-10083-0928
\end{abstract}

\section{INTRODUCTION}

Dental caries is a major oral health problem with high prevalence among children. Worldwide, dental caries persists as a significant public health problem. Food is the most common reason for dental caries. Frequent consumption of carbohydrates in the form of dietary sugar is associated with increased dental caries, which leads to more health problems and dental problems. Dental caries is a multifactorial disease. ${ }^{1}$

Diet is one of the contributing factors to dental caries. Diet plays an important role in the nutritional status and individual development. When diet and oral health are considered, Moynihan states that, "Good diet is essential for the development and maintenance of healthy teeth, but healthy teeth are important in enabling the consumption of a varied and health diet throughout life cycle," thus emphasizing the two-way relationship between diet and oral health. ${ }^{2}$

Nutrition and diet may affect the development and integrity of the oral cavity and the progression of diseases of the oral cavity. Diet has various effects on oral health, primarily on the integrity of the teeth, $\mathrm{pH}$, and composition of the saliva and plaque.

Alterations in nutrient intake secondary to changes in diet intake, absorption, metabolism, or excretion can affect the integrity of the teeth, surrounding tissues, and bone as well as the response to wound healing. The relation between sugar and dental caries is difficult to quantify due to inherent limitations. Variability in patterns of sugars consumption affects the duration of exposure of the teeth to sugars. Consumption of these modern food varieties is more common in children than in adults. ${ }^{2}$
1,2Department of Public Health Dentistry, Indira Gandhi Institute of Dental Sciences, Sri Balaji Vidyapeeth, Puducherry, India

Corresponding Author: Vidhya Gunasekaran, Department of Public Health Dentistry, Indira Gandhi Institute of Dental Sciences, Sri Balaji Vidyapeeth, Puducherry, India, Phone: +91 8870896381, e-mail: vidhyagunasekaran7@gmail.com

How to cite this article: Gunaseelan BV, Gunasekaran V. Prevalence of Dental Caries among Junk Food- and Non-junk Food-eating Schoolchildren in Urban and Rural Areas of Mayiladuthurai, Tamil Nadu, India. J Sci Den 2020;10(1):7-9.

Source of support: Nil

Conflict of interest: None

Children and adolescents form the backbone of future generation, and many serious diseases in adulthood have their roots in adolescence, for example, dietary habits and tobacco usage. Unhealthy lifestyle factors such as skipping meals and food choice leading to a poor nutrient intake are common among this vulnerable adolescent group. Children and adolescents prefer sweetened foods and soft drinks that are rich in carbohydrate and thus are at risk of caries development. ${ }^{2}$

In developing countries, migration of people from rural areas and urbanization causes a change in the lifestyle and dietary habits which in turn affects the oral health. India also shows a similar increase in prevalence with other developing countries. Many surveys regarding oral health have revealed increasing trends in prevalence of dental caries among the children. Socioeconomic 
status, low education status of parents, and parental attitude have impacted the establishment of oral health habits in children. ${ }^{1}$ Thus, this study aims to assess the prevalence of dental caries in junk food- and non-junk food-eating schoolchildren in urban and rural areas in Mayiladuthurai.

\section{Materials and Methods}

A cross-sectional study was conducted among school students in urban and rural areas of Mayiladuthurai district. Study protocol was approved by the Institutional Review Board, and Ethical Committee approval was obtained. A pilot study was carried out among schoolchildren to determine the sample size and also helped in identifying difficulties in the data collection procedure and testing the questionnaire. Simple random sampling method was used. In the first stage, a list of schools were selected in Mayiladuthurai. By means of random sampling, two schools were selected in Mayiladuthurai, one in urban and the other in rural area. Second stage included random selection of children in the specified age-group of 8-11 years. Children in classes 3-5 were the target population in each school. List of students in each school were provided by the school head. Based on inclusion and exclusion criteria, a total of 174 children of aged 12-14 years old were included. Permission was sought from the principals in charge of the schools to carry out the study. Written consent from the principals of the concerned schools was obtained. Information regarding the nature and the need of the study was provided.

\section{Data Collection}

The following information was obtained for the study and incorporated into the questionnaire, considering these to be possible risk indicators for dental caries: type of diet (vegetarian/ nonvegetarian), frequency of eating junk foods, frequency of intake of carbonated drinks, sugar consumption per day, skipping meals (yes/no), and snacking between meals (yes/no).

All children were examined by a single examiner who was trained to record World Health Organization (WHO) oral health assessment form (2013). The children were examined by mouth mirror and explorer under natural light. The WHO oral health assessment form (2013) was used for recording dentition status. The primary investigator explained each question to the student in the presence of the class teacher, and the students were instructed to choose the appropriate answer. Oral examination included screening the children for decayed, missing, filled teeth index using the WHO guidelines. The data obtained were statistically analyzed using SPSS version 15 software and Microsoft excel sheet.

\section{Results}

Table 1 shows that the majority of the participants in this study were urban schoolchildren (66\%) compared to rural schoolchildren (33\%). Table 2 shows that among 59 students in rural school, $80 \%$ had caries and $20 \%$ had no caries. Among 115 students in urban school, $84 \%$ had caries and $16 \%$ had no caries. Compared to rural students, urban schoolchildren are more affected by caries. Table 3 shows

Table 1: Distribution of the schoolchildren among the two groups

\begin{tabular}{lcc}
\hline School & Frequency & Percentage \\
\hline Rural & 59 & 33.9 \\
Urban & 115 & 66.09 \\
Total & 174 & 100 \\
\hline
\end{tabular}

Table 2: Dental caries of schoolchildren among two groups

\begin{tabular}{lll}
\hline Factor & Rural $(n=59)(\%)$ & Urban $(n=115)(\%)$ \\
\hline Dental caries & & \\
Present & $47(80)$ & $97(84)$ \\
Absent & $12(20)$ & $18(16)$ \\
\hline
\end{tabular}

Table 3: Dietary habits of schoolchildren among two groups

\begin{tabular}{lll}
\hline Dietary habits & $\begin{array}{c}\text { Govt school } \\
(n=59)(\%)\end{array}$ & $\begin{array}{l}\text { Private school } \\
(n=115)(\%)\end{array}$ \\
\hline $\begin{array}{l}\text { Type of diet } \\
\text { Vegetarian }\end{array}$ & $13(22)$ & $24(21)$ \\
$\quad$ Nonvegetarian & $46(78)$ & $95(83)$ \\
Skipping meals & & $20(17)$ \\
$\quad$ Yes & $9(15)$ & $95(83)$ \\
No & $50(85)$ & $115(100)$ \\
Snacking in-between meals & 0 \\
Yes & $28(47)$ & \\
No & $31(52)$ & $92(80)$ \\
Intake of junk foods & & $23(20)$ \\
Yes & $46(78)$ & \\
No & $13(22)$ & $85(74)$ \\
Carbonated drinks & & $30(26)$ \\
Yes & $40(68)$ & \\
No & $19(32)$ &
\end{tabular}

that among all students the frequency of intake of nonvegetarian food is higher in urban school (83\%) compated to rural school (78\%). Among all students, skipping meals is higher in urban school (17\%) than in rural school (15\%). Snacking in-between meals is higher in urban school (100\%) compared to rural school (0\%). Intake of junk foods is higher in urban school (80\%) than in rural school (78\%). In-take of carbonated drinks is higher in urban school (74\%) than in rural school (68\%).

\section{Discussion}

Dental caries is a chronic disease that progresses slowly in most people. It is a localized destruction of dental hard tissues by acidic by-products that are released due to bacterial fermentation of dietary carbohydrates. ${ }^{3}$ Dietary sugars, acidic foods, and carbohydrates are the main cause for dental caries. Dietary sugars act as key for dental caries. Dietary habits that were studied were consumption of vegetarian and nonvegetarian diet, skipping of meals, snacking between meals, and frequency of eating in fastfood stalls. ${ }^{2}$

The present study was performed in an attempt to describe the prevalence of dental caries in rural and urban schoolchildren in Mayiladuthurai. The literature review revealed limited studies in this area, thus comparison is limited. Hence the present study was planned and limited.

\section{Distribution}

The present study included a total 174 participants from both rural and private school. The present study is not agreement with Chandrasekar et al. ${ }^{1}$ and Punitha et al. ${ }^{2}$ The possible reason is due to less sample size. 


\section{Dental Caries}

The dentition status was recorded using WHO Proforma (2013). In the present study, dental caries is high among in urban schoolchildren (84\%) which is in agreement with Chandrasekar et al. and Punitha but not in agreement with John et al. ${ }^{4}$, Karjalainen ${ }^{5}$ because it may be due to large sample size. The possible reason for prevalence of dental caries is poor oral hygiene, consumption of cariogenic food, lack of awareness, lack of availability, and dental facilities.

\section{Vegetarian and Nonvegetarian Diet}

In the present study, compared to vegetarian diet, nonvegetarian diet is higher among urban schoolchildren (83\%) compared to rural children (78\%). The present study is in agreement with Chandrasekar et al. and Punitha et al. High intake of nonvegetarian food shows high incidence of dental caries.

\section{Skipping Meals}

In the present study, skipping meals is higher in urban school (17\%) and is not in agreement with Punitha et al. There is no difference in occurrence or severity of caries in children who skipped meals.

\section{Snacking between Meals}

In the present study, snacking between meals is higher among urban schoolchildren (100\%) and is in agreement with Punitha et al. and Chandrasekar et al. The children who snacked in-between meals had higher prevalence of dental caries when compared to those who do not, and this was statistically significant. The possible reason may be because snacking between meals predominantly contain unhealthy junk food with high carbohydrate content and also focused that high exposure to sugar at snacks which increased the risk of caries.

\section{Intake of Junk Foods}

In the present study, intake of junk foods higher in urban school (80\%) and is in agreement with Chandrasekar et al. is not agreement with Gibson et al. ${ }^{6}$ High intake of junk food shows high incidence of dental caries. It is because junk foods are harmful to oral health as they contain sugar substances. Starchy foods such as potato chips, pizza, burgers, and pasta affect our teeth by getting lodged in-between the teeth surfaces. The starchy foods are not sweet or sugary, but as they enter the mouth, these foods get converted into sugars affecting the enamel of teeth. These sugars and salts adhere to the tooth surface and produce acid that erodes the enamel surface of the tooth.

\section{Carbonated Drinks}

In the present study, children who consume carbonated drinks are higher in urban school (74\%), and this is in agreement with Chandrasekar et al. not agreement with Biria et al. ${ }^{7}$ and Aguiar et al. ${ }^{8}$ Risk of caries is high among children consuming soft drinks compared to those who are not. Carbonated drinks contain acids such as phosphoric acid, citric acid, and carbonic acid that destroy the tooth surface causing erosion. Fresh juices can also affect the tooth, as they contain sugars and citrus fruit juices contain acidic substances that cause erosion.

\section{Conclusion}

This study was done to reduce the risk of caries by eliminating the intake of cariogenic food. Our study shows the risk of caries was high among urban schoolchildren.

\section{LIMITATION}

The present study includes convenient sampling and is done in less sample size. Future studies can be explored in large scale to assess the prevalence of dental caries in schoolchildren.

\section{Recommendation}

- Parents should advice the children about the ill effects of frequent consumption of carbonated drinks and junk foods.

- Teachers in schools can educate the children.

- Education on healthy eating habits can bring about behavior changes among these children who would take forward this into their adult life.

\section{References}

1. Chandrasekhar H, Ravindran V, Ganapathy D. Influence of modern food varieties in dental caries among schoolchildren. Drug Invention Today 2019;12(10):2313-2318.

2. Punitha VC, Amudhan A, Sivaprakasam P, Rathanaprabu V. Role of dietary habits and diet in caries occurrence and severity among urban adolescent school children. J Pharm Bioallied Sci 2015;7(Suppl 1): S296-S300. DOI: 10.4103/0975-7406.155963.

3. Mobley C, Marshall TA, Milgrom P, Coldwell SE. The contribution of dietary factors to dental caries and disparities in caries. Acad Pediatr 2009;9(6):410-414. DOI: 10.1016/j.acap.2009.09.008.

4. John JB, Asokan S, Aswanth KP, Priya PG, Shanmugaavel AK. Dental caries and the associated factors influencing it in tribal, suburban and urban school children of Tamil Nadu, India: a cross sectional study. J Public Health Res 2015;4(1):361. DOI: 10.4081/jphr.2015.361.

5. Karjalainen S. Eating patterns, diet and dental caries. Dental Update 2007;34(5):295-298., 300 10.12968/denu.2007.34.5.295.

6. Gibson S, Williams S. Dental caries in pre-school children: associations with social class, toothbrushing habit and consumption of sugars and sugar-containing foods. Caries Res 1999;33(2):101-113. DOI: 10.1159/000016503.

7. Biria M, Amini M, Babaei M, Ahmady AE, Lando HA, Amirabadi GE. Dietary habits and caries experience among 9-year-old school children. J Med Res 2015;2015. DOI: 10.5171/2015.336945.

8. Aguiar BD, Fernandes ME, Aguiar MH, Torquato DS, Peres EC, Teixeira AK. Nutritional status and dental caries of schoolchildren from Sobral-Ceará. RGO Rev Gaúch Odontol 2019;67:e20190049. DOI: 10.1590/1981-86372019000493499. 